\title{
UMA INVESTIGAÇÃO PRELIMINAR DA DESSULFURIZAÇÃO OXIDATIVA DO ÓLEO DIESEL COMERCIAL
}

\author{
A. A. M. M. SANTOS ${ }^{1}$, L. F. SANTOS ${ }^{2}$, A. M. O. SIQUEIRA ${ }^{1}$ \\ ${ }^{1}$ Universidade Federal de Viçosa, Departamento de Química, Programa de Pós-Graduação \\ em Engenharia Química \\ ${ }^{2}$ Faculdade de Ciências Biológicas e da Saúde, UNIVIÇOSA \\ E-mail: aurelio.santos@ufv.br
}

\begin{abstract}
RESUMO: A dessulfurização oxidativa é um método utilizado para a remoção de compostos sulfurosos presentes em combustiveis. É um método que remove esses compostos através de sua oxidação, o que os torna sulfonas que possuem maior polaridade. Este trabalho teve o objetivo de estudar a dessulfurização oxidativa, bem como, analisar a sua eficácia na remoção de compostos sulfurosos presentes em óleo diesel s500 vendido comercialmente, e ainda, avaliar possíveis alterações físico-químicas causadas ao óleo após a realização do procedimento. As reações foram realizadas com 6 amostras à temperatura de $60^{\circ} \mathrm{C}$ e à temperatura ambiente de $24^{\circ} \mathrm{C}$, com e sem catalisadores, com intuito de se analisar a eficiência do processo em diferentes temperaturas. A dessulfurização oxidativa mostrou-se um método que não interfere nas propriedades físico-químicas do diesel. Tanto a massa especifica quanto a viscosidade mantiveram-se dentro do padrão em todas amostras, exceto quando foi utilizado do $\mathrm{MoO}_{3}$ como catalisador, o que causou um aumento em seu índice de acidez.
\end{abstract}

PALAVRAS-CHAVE: Catalisadores; Dessulfurização; Enxofre; Molibdênio; Vanádio.

\section{INTRODUÇÃO}

A poluição atmosférica vem sendo um dos maiores problemas que assolam a sociedade. Com o aumento das emissões atmosféricas, são notáveis os impactos causados pela poluição nas comunidades e no meio ambiente, que são afetados de modo constante pelos níveis elevados de poluição do ar (CETESB, 2011)

A identificação de fontes poluidoras atmosféricas depende de referenciais que possibilitem definir quais são estes agentes e os seus efeitos sobre os seres vivo e também 
depende de critérios que tem por objetivo analisar a frequência de ocorrência destes poluentes na atmosfera (AGUIAR, 2007).

A poluição atmosférica é provocada pela emissão de gases tóxicos que podem ser originados de alguns tipos de combustão. Dentre estes tipos podemos citar a combustão de veículos automotores, que emite óxido de nitrogênio, monóxido e dióxido de carbono, dióxido de enxofre, derivados de hidrocarbonetos e chumbo, responsáveis por $40 \%$ da poluição atmosférica, outra que também pode ser mencionada é a liberação de gases por parte de industriais químicas, siderúrgicas, fábricas de cimento e papel e refinarias de petróleo e de queimadas e incineração de lixo doméstico e industrial (ASSUMPÇÃO et al, 1999).

Dentre todos os compostos emitidos seis deles ganham destaque por serem os mais voláteis, eles são o benzeno, tolueno, etilbenzeno, o-xileno, m-xileno e p-xileno. Além do fator volatilidade eles podem ou não ser cancerígenos, podendo também apresentar efeitos neurotóxicos e mutagênicos (AGUIAR, 2007).

Devido ao fato do dióxido de enxofre $\left(\mathrm{SO}_{2}\right)$ também ser resultante da queima de combustíveis fósseis, este composto tem recebido uma maior atenção por parte dos órgãos governamentais responsáveis. Este composto pode apresentar diversos efeitos prejudiciais a diversas formas de vida (DA SILVA, 2002).

Dentre os compostos de enxofre encontrados na gasolina e no diesel, destacam-se os sulfetos alifáticos, dissulfetos, tiofenos, benzotiofeno, e o dibenzotiofeno, esse destaque deve-se ao fato destes compostos contribuírem efetivamente para o aumento nos índices de poluição atmosférica principalmente em grandes centros urbano, pois quando em combustão estes compostos são convertidos em óxido de enxofre, levando à formação de chuva ácida e de materiais particulados (MCCORMICK, 2005).

Com o intuito de reduzir a emissão de gases poluentes, as indústrias petrolíferas têm investido muito no desenvolvimento de tecnologias para a remoção das partículas de enxofre de combustíveis fósseis, onde a técnica mais convencional utilizada para a remoção é o hidrorefino (GRANGE, 1997).

Este trabalho tem o intuito de estudar a dessulfurização oxidativa, analisar a sua eficácia na remoção de compostos sulfurosos presentes em óleo diesel s500 vendido comercialmente, avaliar possíveis alterações físico-químicas causadas ao óleo após a realização do procedimento, bem como propor um método gravimétrico na quantificação do enxofre total presente no óleo diesel como forma alternativa à cromatografia.

\section{MATERIAIS E MÉTODOS}

\subsection{Materiais}

Para a realização dos experimentos foram utilizados óleo diesel s500, acetonitrila $\left(\mathrm{C}_{2} \mathrm{H}_{3} \mathrm{~N}\right)$, hidróxido de bário $\left(\mathrm{Ba}(\mathrm{OH})_{2}\right)$, hidróxido de potássio $(\mathrm{KOH})$, peróxido de hidrogênio $\left(\mathrm{H}_{2} \mathrm{O}_{2}\right)$ e fenolftaleína $\left(\mathrm{C}_{20} \mathrm{H}_{14} \mathrm{O}_{4}\right)$ como indicador. Como catalisadores foram utilizados o trióxido de molibdênio $\left(\mathrm{MoO}_{3}\right)$ e o pentóxido de vanádio $\left(\mathrm{V}_{2} \mathrm{O}_{5}\right)$.

Foram utilizados os seguintes itens e vidrarias: uma chapa aquecedora, um condensador, cadinhos de porcelana, béqueres de $100 \mathrm{~mL}$, balões de $200 \mathrm{~mL}$, uma bomba de filtração à vácuo, uma estufa e uma balança analítica eletrônica, $215 \mathrm{~g}(0,001 \mathrm{~g})$ modelo FA$2104 \mathrm{~N}$ - Bioprecisa, um picnômetro, buretas de $100 \mathrm{~mL}$, pipetas, erlenmeyers, um 
viscosímetro modelo AVS-350, um termômetro com graduação de $0,1^{\circ} \mathrm{C}$.

\subsection{Métodos}

\section{Dessulfurização oxidativa}

A técnica para a realização da dessulfurização oxidativa foi baseada no procedimento utilizado por Mello (2012). Para a realização de todas as reações de dessulfurização oxidativa foram utilizadas 6 amostras do óleo diesel s500. Para dar início aos experimentos foram adicionados $100 \mathrm{~mL}$ do óleo diesel a um balão de $200 \mathrm{~mL}$, em seguida foram adicionados 50 $\mathrm{mL}$ do solvente extrator acetonitrila, após isso adicionou-se $1 \mathrm{~g}$ de um dos catalisadores escolhidos, o $\mathrm{MoO}_{3}$ ou $\mathrm{V}_{2} \mathrm{O}_{5}$. A reação também foi realizada na ausência de catalisador. $\mathrm{O}$ balão foi colocado em banho maria à temperatura de $60^{\circ} \mathrm{C}$, durante duas horas. Para dar início à reação, adicionou-se $5 \mathrm{~mL}$ de $\mathrm{H}_{2} \mathrm{O}_{2}$, e após uma hora, que corresponde ao tempo de residência para que a reação aconteça, adicionou-se mais $5 \mathrm{~mL}$. A este balão foi acoplado um condensador, formando um sistema de refluxo e as reações ocorreram sob agitação constante. $\mathrm{O}$ mesmo procedimento foi realizado à temperatura ambiente. Ao final, utilizou-se 5 gramas de sulfito de sódio anidro em cada amostra para a retirada da $\mathrm{H}_{2} \mathrm{O}$ presente. $\mathrm{O}$ mesmo procedimento foi realizado com as amostras à temperatura ambiente de $24^{\circ} \mathrm{C}$. Após isso as duas fases, acetonitrila e diesel, foram separadas utilizando-se um funil de separação e devidamente guardadas.

\section{Quantificacão do enxofre}

A técnica utilizada para a quantificação de enxofre total no óleo diesel foi uma adaptação do método utilizado na determinação de enxofre em fertilizantes. A metodologia baseia-se na solubilização e oxidação de todo enxofre presente na amostra pela ação combinada de uma digestão alcalina e oxidação utilizando o peróxido de hidrogênio, essa oxidação transforma todas as formas de enxofre em sulfato, promovendo uma precipitação (MAPA, 2013).

Adicionou-se $50 \mathrm{~mL}$ de uma solução alcalina de hidróxido de potássio a uma amostra de $100 \mathrm{~mL}$ de óleo diesel. Aqueceu-se a solução até sua fervura em uma capela de exaustão por aproximadamente 10 minutos. Após resfriada adicionou-se $30 \mathrm{~mL}$ de peróxido de hidrogênio $30 \%(\mathrm{v} / \mathrm{v})$ e novamente aqueceu-se até próxima de sua fervura por uma hora. Após resfriar novamente adicionou-se $10 \mathrm{~mL}$ de ácido clorídrico concentrado e todo o sistema foi aquecido até a ebulição. Após esta etapa, adicionou-se lentamente $20 \mathrm{~mL}$ de solução de $\mathrm{Ba}(\mathrm{OH})_{2} 100 \mathrm{~g} / \mathrm{L}$, mantendo-se a temperatura entre $80^{\circ} \mathrm{C}$ e $90^{\circ} \mathrm{C}$ por uma hora. Após resfriar, realizou-se uma filtração a vácuo através de papel de filtro quantitativo. $\mathrm{O}$ papel de filtro contendo o precipitado foi então transferido para um cadinho de porcelana e levado a estufa a $110^{\circ} \mathrm{C}$ por quinze minutos para secagem.

\section{Massa específica}

A determinação da massa específica do diesel foi baseada no procedimento descrito por Oliveira et al (2012), que consiste na utilização de um picnômetro. Inicialmente pesou-se o picnômetro vazio e anotou-se sua massa, adicionou-se água destilada e mediu-se a massa da água, fazendo a diferença entra a massa do picnômetro vazio e a massa do picnômetro 
com água destilada obtendo-se a massa de água dentro do picnômetro. A massa específica da água à temperatura ambiente de $29,0^{\circ} \mathrm{C}$ era $0,995 \mathrm{~g} / \mathrm{cm}^{3}$. Calculou-se o volume real do picnômetro através da equação 1 :

$\rho=\frac{\text { Mágua }}{\text { Vreal }}$

Onde, $\rho=$ massa específica da água utilizada, Mágua $=$ massa da água utilizada e $\mathrm{V}_{\text {real }}=$ volume real do picnômetro.

O mesmo picnômetro foi utilizado para se encontrar as massas específicas de cada uma das 6 amostras. Cada uma delas foi inserida para que suas respectivas massas fossem medidas. Após esta etapa dividiu-se a massa de cada uma das amostras pelo volume real do picnômetro, calculando-se assim as respectivas massas específicas.

\section{Índice de acidez}

Para determinar-se o Índice de Acidez foi adaptado o método de Arantes (2008). Foram pesados 2 gramas de cada amostra, que foram adicionados a $300 \mathrm{~mL}$ de solução éter/etanol (2:1) e 3 gotas do indicador fenolftaleína. Essa mistura foi titulada com solução de $\mathrm{KOH} 0,01 \mathrm{~N}$ até o aparecimento da coloração rosa. O cálculo da acidez foi determinado através da seguinte equação 2 .

$A c=\frac{V \cdot f \cdot 5,61}{m}$

Onde, $\mathrm{Ac}=$ Índice de acidez, $\mathrm{f}=$ fator de correção da solução de $\mathrm{KOH}$ correspondente a 1,24, $\mathrm{V}=$ volume de $\mathrm{KOH}, 5,61$ = equivalente grama de $\mathrm{KOH}$ e $\mathrm{m}=$ massa da amostra.

\section{$\underline{\text { Viscosidade }}$}

As medidas de viscosidade foram realizadas no Departamento de Química da Universidade Federal de Viçosa. Foi utilizado um viscosímetro da marca SCHOTT modelo AVS - 350. Utilizando um capilar de $200 \mathrm{com}$ uma constante $\mathrm{k}$ de $0,09148 \mathrm{~mm}^{2} / \mathrm{s}$. No capilar foram adicionados $8 \mathrm{~mL}$ de óleo diesel. A determinação da viscosidade foi realizada pela multiplicação da constante do capilar pelo tempo de queda do óleo. 


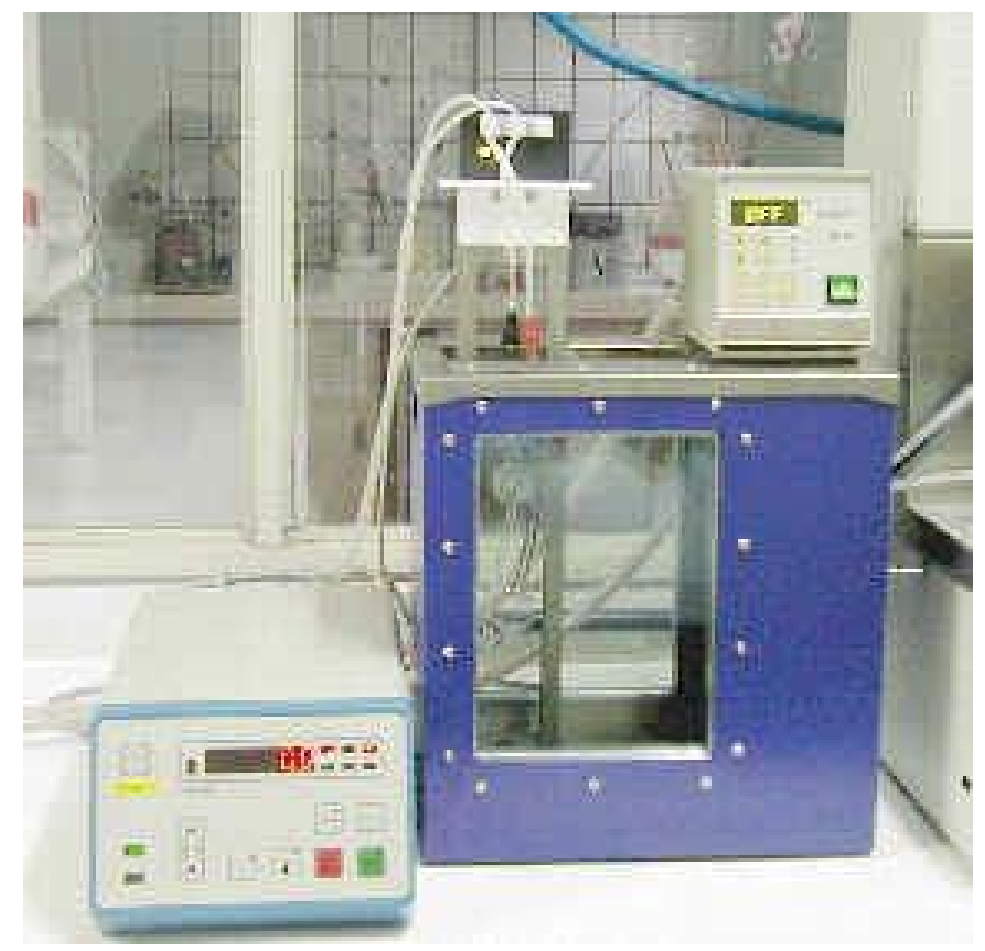

Figura 1 - Viscosímetro SCHOTT AVS - 350.

\section{RESULTADOS E DISCUSSÕES}

\subsection{Dessulfurização oxidativa}

Ao final do processo da dessulfurização oxidativa obteve-se duas fases em cada amostra, a fase do diesel e a fase da acetonitrila, separadas posteriomente. Nas amostras onde utilizou-se os catalisadores $\mathrm{V}_{2} \mathrm{O}_{5}$ e $\mathrm{MoO}_{3}$ a temperatura de $60{ }^{\circ} \mathrm{C}$, a acetonitrila adquiriu uma cor avermelhada. Essa cor é proveniente do processo de oxidação catalítica utilizando-se o $\mathrm{H}_{2} \mathrm{O}_{2}$, que ocorre durante a dessulfurização oxidativa. Nas reações feitas à temperatura ambiente, a acetonitrila também sofreu um processo de oxidação catalítica, mas adquiriu uma cor amarelada, mostrando que o fato de se aumentar a temperatura a $60^{\circ} \mathrm{C}$ influenciou no processo de oxidação, constatação obtida através de uma análise qualitativa visual das amostras.

\subsection{Quantificação do enxofre}

O procedimento proposto para quantificação do teor de enxofre foi realizado em uma amostra de óleo diesel que não foi submetida ao processo da dessulfurização oxidativa. Durante o procedimento obteve-se uma massa amarela gelatinosa. A parte final do experimento foi a filtração que devido à precipitação dos compostos sulfurosos não ter ocorrido da forma prevista impossibilitou que fosse realizada e com isso a quantificação do teor de enxofre não pôde ser realizada. 


\subsection{Propriedade físico-químicas}

As análises físico-químicas foram realizadas tanto para o diesel comercial antes das reações quanto para a fase diesel após a dessulfurização oxidativa.

\subsection{Massa Específica}

Antes da determinação dos valores das massas específicas para as amostras que foram submetidas ao processo de dessulfurização oxidativa, anteriormente a estes valores, a massa específica para a amostra do diesel puro foi calculada e seu valor é $830 \mathrm{~kg} / \mathrm{m}^{3}$.

$\mathrm{Na}$ Tabela 2 estão apresentados os valores da massa específica encontrados para o óleo diesel após as reações de dessulfurização oxidativa realizada à temperatura ambiente.

Tabela 2. Massas específicas do diesel após as reações à temperatura ambiente.

\begin{tabular}{cc}
\hline Reações & $\boldsymbol{\rho}\left(\mathbf{k g} / \mathbf{m}^{\mathbf{3}}\right)$ \\
\hline $\mathbf{M o O}_{3}$ & $849,99 \pm 0,05$ \\
$\mathbf{V}_{\mathbf{2}} \mathbf{O}_{\mathbf{5}}$ & $829,99 \pm 0,05$ \\
Sem catalisador & $849,99 \pm 0,05$ \\
\hline
\end{tabular}

$\mathrm{Na}$ Tabela 3 estão apresentados os valores para as massas específicas após as amostras serem submetidas ao processo de dessulfurização oxidativa à temperatura de $60^{\circ} \mathrm{C}$.

Tabela 3. Massas específicas do diesel após as reações a $60^{\circ} \mathrm{C}$.

\begin{tabular}{cc}
\hline Reações & $\boldsymbol{\rho}\left(\mathbf{g} / \mathbf{c m}^{\mathbf{3}}\right)$ \\
\hline $\mathbf{M o O}_{3}$ & $840,01 \pm 0,05$ \\
$\mathbf{V}_{\mathbf{2}} \mathbf{O}_{5}$ & $840,01 \pm 0,05$ \\
Sem catalisador & $840,01 \pm 0,05$ \\
\hline
\end{tabular}

Conforme mostrado nas tabelas 2 e 3 , as massas especificas de cada amostra não sofreram nenhum tipo de alteração devido à dessulfurização oxidativa, os valores encontrados mantiveram-se dentro das especificações do diesel brasileiro que é de $800 \mathrm{~kg} / \mathrm{m}^{3}$. Os resultados encontrados comparam-se aos de Medeiros et al (2003), onde os valores apresentados em seu trabalho também se mantiveram dentro do padrão estabelecido. Manter a massa específica dentro do padrão evita que haja maior emissão de partículas sólidas na atmosfera durante a combustão.

\section{5. Índice de acidez}

Inicialmente o valor para o Índice de Acidez foi determinado para o diesel puro, e o valor encontrado foi de $0,34 \mathrm{mg} \mathrm{KOH} / \mathrm{g}$. Na Tabela 4 estão apresentados os valores do Índice 
de Acidez para as amostras de diesel após as reações de dessulfurização oxidativa à temperatura ambiente.

Tabela 4. Índice de Acidez após as reações à temperatura ambiente.

\begin{tabular}{cc}
\hline Reações & $\begin{array}{c}\text { Índice de Acidez } \\
\text { (mg KOH/g) }\end{array}$ \\
\hline $\mathbf{M o O}_{3}$ & $1,73 \pm 0,05$ \\
$\mathbf{V}_{\mathbf{2}} \mathbf{O}_{5}$ & $0,34 \pm 0,01$ \\
Sem catalisador & $0,34 \pm 0,01$ \\
\hline
\end{tabular}

Na Tabela 5 estão apresentados os valores do Índice de Acidez para as amostras obtidos após a dessulfurização oxidativa à temperatura de $60^{\circ} \mathrm{C}$.

Tabela 5. Índice de Acidez após as reações à $60^{\circ} \mathrm{C}$.

\begin{tabular}{cc}
\hline Reações & $\begin{array}{c}\text { Índice de Acidez } \\
(\mathbf{m g ~ K O H} / \mathbf{g})\end{array}$ \\
\hline $\mathbf{M o O}_{3}$ & $1,73 \pm 0,05$ \\
$\mathbf{V}_{\mathbf{2}} \mathbf{O}_{5}$ & $0,34 \pm 0,01$ \\
Sem catalisador & $0,34 \pm 0,01$ \\
\hline
\end{tabular}

As Tabelas 4 e 5 mostram que o processo de dessulfurização oxidativa utilizando o $\mathrm{V}_{2} \mathrm{O}_{5}$ ou sem catalisadores não causou nenhuma alteração no Índice de Acidez. Já as reações utilizando o catalisador $\mathrm{MoO}_{3}$ tanto à $60^{\circ} \mathrm{C}$ quanto à temperatura ambiente que era de $24^{\circ} \mathrm{C}$ proporcionaram um aumento neste parâmetro, apresentando resultados superiores ao permitido pela ANP (Agência Nacional de Petróleo) que é de $0,8 \mathrm{mg}$ de $\mathrm{KOH} / \mathrm{g}$, isso se deve ao fato do $\mathrm{MoO}_{3}$ ser um óxido ácido e sua utilização ter provacado um aumento no Índice de Acidez do diesel. Os resultados encontrados para as amostras onde não foi utilizado o $\mathrm{MoO}_{3}$ como catalisador são comparáveis aos de Souza et al (2009), que também se mantiveram abaixo do padrão determinado pela ANP.

\subsection{Viscosidade}

Antes das viscosidades de cada amostra serem determinadas, a viscosidade do óleo diesel foi encontrada permitindo tê-la como um parâmetro de comparação. A viscosidade encontrada para o diesel puro foi de $5,20 \mathrm{~mm}^{2} / \mathrm{s}$. Na Tabela 6 são apresentados os valores encontrados para viscosidade do óleo diesel após a realização da dessulfurização oxidativa à temperatura ambiente. 
Tabela 6 Viscosidades após as reações à temperatura ambiente.

\begin{tabular}{cc}
\hline Reações & Viscosidade $\left(\mathbf{m m}^{\mathbf{2}} \mathbf{s}\right)$ \\
\hline $\mathbf{M o O}_{3}$ & $5,27 \pm 0,13$ \\
$\mathbf{V}_{\mathbf{2}} \mathbf{O}_{5}$ & $5,28 \pm 0,09$ \\
Sem catalisador & $5,30 \pm 0,15$ \\
\hline
\end{tabular}

$\mathrm{Na}$ Tabela 7 estão apresentados os valores encontrados para as viscosidades do óleo diesel após a dessulfurização oxidativa à $60^{\circ} \mathrm{C}$.

Tabela 7: Viscosidades após as reações à $60^{\circ} \mathrm{C}$.

\begin{tabular}{cc}
\hline Reações & Viscosidade $\left(\mathbf{m m}^{2} / \mathbf{s}\right)$ \\
\hline $\mathbf{M o O}_{3}$ & $5,30 \pm 0,15$ \\
$\mathbf{V}_{2} \mathbf{O}_{5}$ & $5,29 \pm 0,15$ \\
Sem catalisador & $5,26 \pm 0,15$ \\
\hline
\end{tabular}

Como mostrado nas Tabelas 6 e 7 o procedimento de dessulfurização oxidativa não provocou alterações nas viscosidades das amostras analisadas. Todas as amostras mantiveram-se do padrão para o óleo diesel. Os resultados encontrados neste trabalho comparam-se aos de Aleme (2011) que se mantiveram entre $2,39 \mathrm{~mm}^{2} / \mathrm{s}$ e $4,83 \mathrm{~mm}^{2} / \mathrm{s}$, mantendo-se dentro do padrão adotado pela Agência Brasileira de Engenharia Automotiva (AEA), estabelecido através na NBR 10441 que descreve um método para o cálculo da viscosidade de combustíveis. A manutenção da viscosidade dentro do padrão estabelecido proporciona a manutenção das propriedades lubrificantes do diesel.

\section{CONCLUSÕES}

Após a realização dos experimentos foi possível averiguar que o método alternativo proposto para a quantificação do enxofre total não se mostrou eficiente, isso se deve à precipitação insatisfatória dos compostos sulfurosos presentes, o que tornou impossível a realização de uma boa filtração e a determinação da eficiência.

Concluiu-se também que o processo de dessulfurização oxidativa não provocou alterações nas propriedades físico-químicas do óleo diesel, quando realizado na ausência de catalisadores ou mesmo quando utilizado o Pentóxido de Vanádio $\left(\mathrm{P}_{2} \mathrm{O}_{5}\right)$ como catalisador. Percebeu-se que de todas as propriedades analisadas a única que sofreu alguma alteração foi o Índice de Acidez, mostrando um aumento significativo após a realização da dessulurização utilizando Trióxido de Molibdênio $\left(\mathrm{MoO}_{3}\right)$ como catalisador. Este parâmetro alcançou o valor de $1,34 \mathrm{mg} \mathrm{KOH} / \mathrm{g}$, o que ultrapassa em grande quantidade o valor permitido pela Agência Nacional de Petróleo, que é de $0,8 \mathrm{mg} \mathrm{KOH} / \mathrm{g}$. A partir deste resultado obtido constatou-se que a utilização desse catalisador no processo não é viável, pois causou uma alteração significante, mesmo que em apenas uma propriedade físico-química do óleo diesel. 


\section{REFERÊNCIAS}

ANP, AGÊNCIA NACIONAL DO PETRÓLEO; Portaria No 255, de 15 de setembro de 2003; Especificação para o biodiesel puro a ser adicionado ao óleo diesel automotivo. Disponível em: Acesso em: 10 out 2009.

AGUIAR, A.C.S. Dessulfurização oxidativa da mistura dibenzotiofeno/isoctano. 2007. 104 f. Dissertação (Mestrado em Engenharia Química) - Universidade Federal de Pernambuco, Recife.

ALEME, H. Determinação de parâmetros físico-químicos do óleo diesel a partir de curvas de destilação utilizando técnicas quimiométricas. 2011. 149f. Tese (Doutorado em Química) - Instiuto de Ciências Exatas da Universidade Federal de Minas Gerais.

ALI, M. F.; AL-MALKI, A.; EL-ALI, B.; MARTINIC, G.; SIDDIQUI, M. N.. "Deep desulphurization of gasoline and diesel fuels using on-hydrogen consuming techniques". Fuel 85, $1354-1363,2006$.

ALVES, L.; MESQUITA, E.; GÍRIO, F. M. Dessulfurização Bacteriana de Combustíveis Fósseis. Boletim de Biotecnologia, n 62, 2010.

ARANTES, A. C.C et al. Avaliação do Índice de Acidez e do Índice de Saponificação de óleos residuais durante $\mathrm{o}$ armazenamento. $5^{\circ}$ Congresso Brasileiro de Plantas Oleaginosas, Óleos, Gorduras e Biodiesel, Lavras, 2008.

BRACHT, F. Método de preparação industrial de solventes e reagentes químicos. Revista Virtual de Química. Rio de Janeiro, v.3, n.1, p. 51-52, mar/abr. 2011.

BRITO, M.; "Biodiesel: o caminho certo", O Estado de S. Paulo, 09/06/2004.

CAERO, L. C.; NAVARRO, A; JORGE, F.; GUTIÉRREZ-ALEJANDRE, A.; "Oxidative desulfurization of synthetic diesel using supported catalysts Part II. Effect of oxidation and nitrogen-componds on extraction-oxidation process"; Catalysis Today 116, $562-568,2006$.

CAMPOS-MARTIN, J. M.; CAPEL-SANCHEZ, M. C.; PEREZ-PRESAS, P.; FIERRO, J. L. G. Oxidative process of desulfurization of liquid fuels. Journal of Chemical Technology e Biotechnology, v. 85, n. 7, p. 879-890, 2010.

CATALUÑA, R.; SILVA, E.; CARDOSO, G.; RUSCHCEL, R.; SILVA, R. O efeito do número de cetano nas emissões de Material Particulado em veículos ciclo Diesel. 2012. Trabalho acadêmico - Universidade Federal do Rio Grande do Sul. Bento Gonçalves, 2012.

CETESB. Qualidade do Ar no Estado de São Paulo. 2011. Governo do Estado de São Paulo - Secretaria do Meio Ambiente, Companhia Ambiental do Estado de São Paulo. São Paulo, SP.

CONSELHO REGIONAL DE QUÍMICA - IV REGIÃO, Catalisadores. Disponível em < http://www.crq4.org.br/quimica_viva_catalisadores > . Acessado em 10/11/2015 às 23.24 .

CRUZ, T.G.S. Intercalação de lítio em filmes finos de óxido de molibdênio. 1998. 64 f. Dissertação (Mestrado em Física) - Universidade de Campinas, Campinas.

GONZALEZ-GARCIA, O.; CEDEÑO-CAERO, L. V-Mo based catalysts for oxidative desulfuration of diesel fuel. Catalysis Today. V.148, n. 1-2, p. 42-48, 2009.

DA Silva, M. G. C., Gimenes, M. L., AQUinO, A.D., BARbOSA, C. M. B. M, E 
MEDEIROS, S. H. W. “Adsorção de SO2 em Leito Fluidizado de Zeólita”, Cd-room Anais do Cong. Bras. Eng. Quim. - COBEQ, Natal-Brasil, 2002.

AGÊNCIA NACIONAL DE ENGENHARIA AUTOMOTIVA; Especificações do óleo diesel.

$<$ Disponível

em

http://www.aea.org.br/aea2009/downloads/simpcombustiveis/09h40-

RosangelaMoreira-Adicional04.pdf $>$. Acessado em 23/11/2016.

FARO JÚNIOR, A. C., "Curso de Catálise - Catalisadores de Processos catalíticos, Os Sulfetos e os Hidrotratamentos", São Paulo-SP, editado pelo Instituto Brasileiro de Petróleo, 29 de agosto a 02 de setembro, p. 57, 1994.

FERREIRA, Análise por cromatografia gasosa de btex nas emissões de motor de combustão interna alimentado com diesel e mistura diesel-biodiesel (b10). Quimica. Nova, São Carlos, v. 31, n. 3, p. 539-545, mar, 2008.

GRANGE, P.; VANHAEREN, X. "Hidrotreating catalysts, an old story with new challenges". Catalysis Today, 36, 375-391, 1997.

GROSSMAN, M. J.; LEE, M. K.; PRINCE, R. C.; MINAK-BERNERO, V.; GEORGE, G. N. and PIKERING, I. J., "Deep Desulfurization of Extensively Hydrodesulfurized Middle Distillate Oil by Rhodococcus sp. Strain ECRD-1", Applied and Environmental Microbiology, 67(4), 1949-1952, 2001.

IRVINE, R.- "Consider Latest Low Cost Breakthrough For Low Sulfur Gasoline", LA, publication of the Hart Energy Group, p. 18-19 Summer, 1999.

LEGRINI, O.; OLIVEROS, E; BRAUN, A.M. Photochemical process for water treatement. Chemical. Rev., v. 93, n. 2, p. 671-698, 1993.

LIOTTA, F. and HAN, Y., "Production of ultra-low sulfurfuels by selective hydroperoxide oxidation", Proceedings of the NPRA Annual Meeting, San Antonio, TX, 2003.

LÔBO, I.P.; FERREIRA, S.L.C. Biodiesel: Parâmetros de qualidade e métodos analíticos. Química Nova, v. 32, n. 6, p. 1596-1608, 2009.

MAPA; Manual de métodos analíticos oficiais para fertilizantes e corretivos, Brasília, 2013.

MEDEIROS, M.A.O.; ARAÚJO, A.S.; FERNANDES, N.S. Estudo comparativo das propriedades físico-químicas do óleo diesel combustível nos Estados do RN e PB. In: Congresso Brasileiro de P\&D em Petróleo e Gás. 2., 2003, Rio de Janeiro. Departamento de Química, Lagoa Nova, 2003.

MELLO, M.I.S. Dessulfurização oxidativa em diesel utilizando catalisadores à base de vanádio e manganês. 2012. 157 f. Dissertação (Mestrado em Química) - Universidade Federal do Rio Grande do Norte, Natal.

MCCORMICK, B. "Effects of Biodiesel on Pollutant Emissions." National Renewable Energy Laboratory Report. Golden, Colorado. March 16, 2005.

MORAES, M. Biodisel de sebo: Avaliação de propriedades e testes de consumo e motor diesel. 2008. 105f. Tese de Mestrado em Química - Instituto de Química, Universidade Federal do Rio Grande do Sul, Porto Alegre, 2008.

OLIVEIRA, A.K.C. et al. Produção e avaliação comparativa do biodiesel de soja e biodiesel de linhaça através de dois métodos de preparação aplicados aos óleos vegetais. VII CONNEPI, 2012.

RAGNINI, C. A. R; IGLIA, R. A. D.; BERTAZZOLI, R. Considerações sobre a eletrogeração de peróxido de hidrogênio. Química. Nova. Dados, v. 24, n. 2, p.252- 
$256,2001$.

SANTOS, J.H.L. "Remoção de Enxofre da Mistura Propanotiol/Ciclo-Hexeno em Sistema a Leito Fixo Utilizando Adsorvente Ni/NaY". Dissertação de Mestrado, Universidade Federal de Pernambuco, p. 127, 2005.

SHOREY, S. W. et al. - "Improve Refinery Margins and Produce Low-Sulfur Fuels", IL, publication of the Hart Energy Group, p. 41-42, 1999.

SOUZA, C. D. R.; CHAAR, J. S; SOUZA, R.C.R.; JEFFREYS, M.F.; SOUZA, K.S.;

COSTA, J.C. Caracterização físico-química das misturas binárias de biodiesel e diesel comercializados no Amazonas, Amazonas. Acta Amazonica, Vol. 39, pag 383, 2009.

SPEIGHT, J. G, "Petroleum Chemistry and Refining". II Series, Cap 8 e 11, p. 8-29 e $1129,1998$.

SRVISTAVA, V. C. An evalution of desulfurization techonologies for sulfur removal from liquid fuels. The Royal Society of Chemistry, v.42, 2011.

TEIXEIRA, E. C; FELTES, S; SANTANA, E. R. R. Estudo Das Emissões De Fontes Móveis Na Região Metropolitana De Porto Alegre, Rio Grande Do Sul. Química Nova, Vol. 31, pag 244, 2008.

ULlER, A., PEREIRA, R., COHEN, B., MENDES, M., T. RODRIGUES, H. Projeto CTPETRO Tendências tecnológicas. Nota técnica 07: Capacidade Inovativa do Segmento Refino, 2003.

WACHS, Catalysis science of supported vanadium oxide catalysts. Dalton Transactions, London, n. 42, p. 11762-11769, apr, 2013. 


\title{
A PRELIMINARY INVESTIGATION OF OXIDATIVE DESULFURIZATION OF COMMERCIAL DIESEL
}

\author{
A. A. M. M. SANTOS ${ }^{1}$, L. F. SANTOS ${ }^{2}$, A. M. O. SIQUEIRA ${ }^{1}$ \\ ${ }^{1}$ Universidade Federal de Viçosa, Departamento de Química, Programa de Pós-Graduação \\ em Engenharia Química \\ ${ }^{2}$ Faculdade de Ciências Biológicas e da Saúde, UNIVIÇOSA \\ E-mail: aurelio.santos@ufv.br
}

\begin{abstract}
The oxidative desulphurization is considerate one of the most promising methods to remove sulphurous compounds of fossil fuels, because it's a process that can be realized under smooth conditions, ambient temperature and atmospheric pressure. Oxidative desulphurization reactions were carried out with 6 samples at a temperature of $60^{\circ} \mathrm{C}$ and $24^{\circ} \mathrm{C}$ ambient temperature, with and without catalysts, in order to analyze the efficiency of the process at different temperatures. The analyzes of the physico-chemical properties are of great importance to analyze possible changes because of the reactions. The proposed method to quantify the sulfur content was made, but because of the unsatisfying precipitation of the sulfurous compounds your efficiency could not be calculated. The oxidative desulfurization was found to be a method that does not affect the physico-chemical properties of the diesel engine, both the density and the viscosity remained in the pattern in all samples except when it was used in the $\mathrm{MoO}_{3}$ as catalyst, which caused an increase in its acidity level.
\end{abstract}

KEYWORDS: Catalysts. Desulphurization. Molybdenum; Sulfur; Vanadium. 